\title{
Redução da proteína bruta em rações sobre os balanços metabólicos de suínos mantidos em diferentes condições térmicas
}

\section{Reducing crude protein in diets on the metabolic balances for pigs kept in different thermal conditions}

\author{
Debora Cristiane Freitagi' Élcio Silvério Klosowski²; Paulo Cesar Pozza ${ }^{3}$; Aparecida da \\ Costa Oliveira ${ }^{4}$; Claúdio Yuji Tsutsumi ${ }^{5}$; Ricardo Vianna Nunes ${ }^{6}$; Cleiton Pagliari Sangali ${ }^{7}$
}

\begin{abstract}
Resumo
O objetivo deste trabalho foi avaliar a redução da proteína bruta em rações sobre o balanço de nitrogênio, $\mathrm{pH}$ urinário e parâmetros sanguíneos de suínos na fase inicial. O peso médio inicial dos animais foi de $18,5 \pm 0,73 \mathrm{~kg}$. Foram realizados dois experimentos de digestibilidade, sendo um em condições de ambiente de estresse $\left(28,77^{\circ} \mathrm{C}\right)$ e outro conforto térmico $\left(18,13^{\circ} \mathrm{C}\right)$. Em ambos os experimentos os animais foram distribuídos em um delineamento experimental de blocos ao acaso com quatro níveis de proteína bruta $(20,5$; 19,$4 ; 18,3$ e $17,2 \%$ ) e quatro repetições, totalizando 16 unidades experimentais em cada experimento, sendo cada uma representada por um animal, totalizando 32 animais. A metodologia utilizada foi a coleta total de fezes, e a urina coletada e filtrada diariamente. Para avaliar os parâmetros sanguíneos, as amostras foram obtidas mediante punção na veia jugular. Os parâmetros avaliados foram nitrogênio ingerido, excretado nas fezes e na urina, absorvido, retido, retido/absorvido, excreção total, utilização líquida de proteína, $\mathrm{pH}$ da urina, colesterol, triglicerídeos, glicose, uréia e creatinina no plasma sanguíneo. Conclui-se que a redução do nível de proteína da dieta, de 20,5 a 17,2\%; é uma alternativa eficiente para reduzir a quantidade de nitrogênio excretado pelos suínos em condição de estresse térmico. Para condição de conforto térmico os suínos apresentaram maiores concentrações de creatinina e colesterol plasmático.
\end{abstract}

Palavras-chave: Aminoácidos. Ambiente térmico. Metabolismo de nitrogênio.

\begin{abstract}
The objective of this study was to evaluate the reduction of crude protein diets on nitrogen balance, urinary $\mathrm{pH}$ and blood parameters of starter pigs. The average initial weight of the animals was $18.5 \pm 0.73 \mathrm{~kg}$. Two digestibility experiments were conducted, one in environmental conditions of stress $\left(28.77^{\circ} \mathrm{C}\right)$ and another in thermal comfort condition $\left(18.13^{\circ} \mathrm{C}\right)$. In both experiments, the animals were distributed in randomized blocks with four decreasing levels of crude protein $(20.5,19.4,18.3$ and $17.2 \%)$ and four replications, totaling 16 experimental units in each experiment, each represented by an animal, totaling 32 animals. The methodology used was the total collection of feces and urine was collected and filtered daily. To assess blood parameters, samples were obtained by jugular vein puncture. The parameters evaluated were ingested nitrogen, excreted
\end{abstract}

\footnotetext{
${ }^{1}$ Mestre em Zootecnia pela Universidade Estadual do Oeste do Paraná. E-mail: deborafreitag@gmail.com

${ }^{2}$ Doutor em Agronomia pela Universidade Estadual Paulista Júlio de Mesquita Filho. Professor Associado da Universidade Estadual do Oeste do Paraná. elciosk1@yahoo.com.br

${ }^{3}$ Doutor em Zootecnia pela Universidade Federal de Viçosa. Professor associado da Universidade Estadual de Maringá. E-mail: pcpozza@uem.br

${ }^{4}$ Doutoranda em Zootecnia pela Universidade Federal da Paraíba. E-mail: aparecidacostaoliveira@gmail.com

${ }^{5}$ Doutor em Agronomia pela Universidade de São Paulo. Professor adjunto da Universidade Estadual do Oeste do Paraná. E-mail: claudio.tsutsumi@unioeste.br

${ }^{6}$ Doutor em Zootecnia pela Universidade Federal de Viçosa. Professor associado da Universidade Estadual do Oeste do Paraná nunesrv@hotmail.com.br

${ }^{7}$ Doutorando em Zootecnia pela Universidade Estadual de Maringá. E-mail: sangalicp@hotmail.com
} 
in feces and urine, absorbed, retained, retained/absorbed, total excretion, net protein utilization, urine $\mathrm{pH}$, cholesterol, triglycerides, glucose, urea and creatinine in blood plasma. It is concluded that reducing the level of protein in the diet, 20.5 to $17.2 \%$; is an efficient alternative to reduce the amount of nitrogen excreted by pigs in heat stress condition. In thermal comfort condition pigs showed higher concentration of creatinine and serum cholesterol.

Key words: Amino acids. Thermal environment. Nitrogen metabolism.

\section{Introdução}

O sistema de criação intensiva de suínos origina grandes quantidades de resíduos. Portanto, há uma grande preocupação com a melhoria da produtividade e redução da emissão de poluentes ao meio ambiente. A concentração de nitrogênio nas fezes é relativamente alta e o excesso é convertido em substâncias como nitrato e amônia, que são prejudiciais ao meio ambiente, ao desempenho dos animais e para a saúde de animais e seres humanos.

Os avanços na determinação das exigências de aminoácidos para suínos, associada a um aumento da disponibilidade de aminoácidos sintéticos, permite a redução dos níveis de proteína bruta da dieta, com o objetivo de fornecer aos suínos uma relação equilibrada de aminoácidos que atendam as suas necessidades, proporcionando maior eficiência de deposição de proteína e menor excreção de nitrogênio (TOLEDO et al., 2014).

Além disso, a utilização de aminoácidos sintéticos nas dietas constitui uma alternativa nutricional utilizada para melhorar a produtividade dos suínos alojados em ambientes de altas temperaturas (RODRIGUES et al., 2012), pois os suínos são mais sensíveis às temperaturas elevadas e esta sensibilidade é devida a uma combinação de fatores, entre os quais um sistema de termorregulação de baixa eficácia, glândulas sudoríparas queratinizadas, a presença de uma camada de gordura subcutânea e um metabolismo intenso (WOLP et al., 2012).

Portanto, umaalternativaéa utilização de rações com baixos níveis de proteína bruta e suplementação de aminoácidos sintéticos, principalmente quando as temperaturas ambientais ultrapassam os níveis de conforto térmico. Várias pesquisas foram realizadas com o intuito de avaliar a redução da proteína bruta em rações para suínos sobre o balanço de nitrogênio, no entanto, a avaliação sob diferentes condições ambientais deve ser considerada, uma vez que o incremento calórico das dietas é alterado em função da redução da proteína bruta e a respectiva suplementação de aminoácidos sintéticos.

Desta forma, o objetivo deste trabalho foi avaliar a redução da proteína bruta em rações para suínos, com a respectiva suplementação de aminoácidos sintéticos, sobre o balanço de nitrogênio, parâmetros sanguíneos e urinários, em condições de estresse e conforto térmico.

\section{Material e Métodos}

Foram realizados dois experimentos de digestibilidade na Fazenda Experimental da Universidade Estadual do Oeste do Paraná UNIOESTE, Campus Marechal Cândido Rondon, sendo um realizado em condição de estresse térmico e outro realizado em condição de conforto térmico.

Para o experimento realizado em condições de estresse térmico $\left(28,8^{\circ} \mathrm{C}\right)$ foram utilizadas placas térmicas elétricas para o aquecimento do ambiente, acionadas quando a temperatura ambiente encontravase abaixo de $30,0^{\circ} \mathrm{C}$. Para o experimento realizado em condição de conforto térmico $\left(18,13{ }^{\circ} \mathrm{C}\right)$ foi utilizado um ar condicionado do tipo Split (12000 BTUs), automaticamente acionado quando a temperatura do ambiente ultrapassasse os $21,0{ }^{\circ} \mathrm{C}$. As condições ambientais da sala foram monitoradas às $08 \mathrm{~h} 00 \mathrm{~min}$, $11 \mathrm{~h} 00 \mathrm{~min}, 14 \mathrm{~h} 00 \mathrm{~min}$ e $17 \mathrm{~h} 00 \mathrm{~min}$, com auxílio de um Datalogger Homis ${ }^{\circledR}$, modelo 494.

Em cada experimento foram utilizados 16 suínos, machos e castrados, individualmente alojados em gaiolas de metabolismo semelhante às descritas por Pekas (1968), totalizando 32 animais com peso médio 
inicial de $18,5 \pm 0,7 \mathrm{~kg}$. O delineamento experimental utilizado em ambos os experimentos foi o de blocos ao acaso, constituído por quatro tratamentos e quatro repetições.

Os tratamentos consistiram em quatro níveis decrescentes de proteína bruta (20,5; 19,4; 18,3 e 17,2\%). Os mesmos tratamentos foram utilizados nos dois experimentos, diferindo apenas na condição ambiental em que os animais foram submetidos (estresse térmico e conforto térmico).

Tabela 1 - Composição centesimal das rações experimentais, na matéria natural.

\begin{tabular}{|c|c|c|c|c|}
\hline \multirow[t]{2}{*}{ Ingredientes (\%) } & \multicolumn{4}{|c|}{ Proteína bruta (\%) } \\
\hline & 20,5 & 19,4 & 18,3 & 17,2 \\
\hline Milho & 63,50 & 66,50 & 69,45 & 72,70 \\
\hline Farelo de soja & 31,50 & 28,30 & 24,95 & 21,47 \\
\hline Casca de soja & 0,00 & 0,20 & 0,42 & 0,62 \\
\hline Óleo de soja & 1,18 & 1,06 & 0,99 & 0,75 \\
\hline Fosfato bicálcico & 1,60 & 1,60 & 1,60 & 1,60 \\
\hline Calcário & 0,62 & 0,62 & 0,63 & 0,63 \\
\hline Bicarbonato de sódio & 0,00 & 0,11 & 0,23 & 0,35 \\
\hline Antioxidante1 & 0,02 & 0,02 & 0,02 & 0,02 \\
\hline Sal comum & 0,46 & 0,38 & 0,30 & 0,24 \\
\hline Mistura mineral2 & 0,05 & 0,05 & 0,05 & 0,05 \\
\hline Mistura vitamínica3 & 0,10 & 0,10 & 0,10 & 0,10 \\
\hline L-Lisina $\mathrm{HCl}$ & 0,23 & 0,31 & 0,39 & 0,47 \\
\hline DL-Metionina & 0,07 & 0,10 & 0,13 & 0,16 \\
\hline L-Treonina & 0,07 & 0,11 & 0,16 & 0,20 \\
\hline L- Valina & 0,00 & 0,01 & 0,07 & 0,12 \\
\hline L- Isoleucina & 0,00 & 0,00 & 0,00 & 0,04 \\
\hline L- Triptofano & 0,00 & 0,00 & 0,02 & 0,03 \\
\hline Cloreto de colina & 0,04 & 0,05 & 0,09 & 0,09 \\
\hline Fosfato de tilosina & 0,18 & 0,18 & 0,18 & 0,18 \\
\hline Inerte 4 & 0,38 & 0,30 & 0,22 & 0,18 \\
\hline \multicolumn{5}{|l|}{ Composição } \\
\hline Energia metabolizável (kcal/kg) & 3230 & 3230 & 3230 & 3230 \\
\hline Proteína bruta $(\%) 5$ & 20,500 & 19,400 & 18,300 & 17,200 \\
\hline Proteína digestível (\%) & 18,000 & 17,000 & 16,000 & 15,000 \\
\hline Cálcio (\%) & 0,720 & 0,720 & 0,720 & 0,720 \\
\hline Fósforo disponível (\%) & 0,400 & 0,400 & 0,400 & 0,400 \\
\hline Sódio (\%) & 0,200 & 0,200 & 0,200 & 0,2085 \\
\hline Potássio (\%) & 0,755 & 0,704 & 0,651 & 0,596 \\
\hline Cloro (\%) & 0,319 & 0,275 & 0,226 & 0,190 \\
\hline Lisina digestível (\%) & 1,145 & 1,145 & 1,145 & 1,145 \\
\hline Treonina digestível (\%) & 0,721 & 0,721 & 0,721 & 0,721 \\
\hline Met + Cis digestivel (\%) & 0,641 & 0,641 & 0,641 & 0,641 \\
\hline Metionina digestível (\%) & 0,355 & 0,368 & 0,382 & 0,397 \\
\hline Triptofano digestível (\%) & 0,211 & 0,196 & 0,195 & 0,195 \\
\hline Arginina digestivel (\%) & 1,234 & 1,143 & 1,049 & 0,950 \\
\hline Valina digestivel (\%) & 0,828 & 0,790 & 0,790 & 0,790 \\
\hline Leucina digestível (\%) & 1,603 & 1,529 & 1,451 & 1,371 \\
\hline Isoleucina digestível (\%) & 0,752 & 0,699 & 0,644 & 0,630 \\
\hline Histidina digestivel (\%) & 0,483 & 0,456 & 0,428 & 0,398 \\
\hline Fenilalanina digestível (\%) & 0,888 & 0,833 & 0,775 & 0,716 \\
\hline Fenilalanina + tirosina dig. (\%) & 1,478 & 1,388 & 1,294 & 1,196 \\
\hline $\operatorname{BED}^{6}(\mathrm{Meq} / \mathrm{kg})$ & 189,97 & 189,56 & 189,73 & 189,57 \\
\hline
\end{tabular}

1 BHT. 2 Conteúdo/kg: ferro $100 \mathrm{~g}$; cobre $10 \mathrm{~g}$; cobalto

$1 \mathrm{~g}$; manganês $40 \mathrm{~g}$; zinco $100 \mathrm{~g}$; iodo $1,5 \mathrm{~g}$; e veículo q.s.p. p/ 1000 g. 3 Conteúdo/kg: vit. A, 10.000.000 U.I.; vit D3, 1.500 .000 U.I.; vit. E, 30.000 U.I.; vit B1- 2,0 g; vit B2 - 5,0 g; vit. B6 - 3,0 g; vit B12 - 30.000 mcg; ácido nicotínico, $30.000 \mathrm{mcg}$; ácido pantotênico 12.000 mcg; vit. K3, $2.000 \mathrm{mg}$; ácido fólico, $800 \mathrm{mg}$; biotina, 100 mg; selênio, 300 mg; e veículo q.s.p. p/ 1000 g. 4 Areia fina lavada. 5 Valores determinados no Laboratório de Nutrição Animal da UNIOESTE, 6 Balanço eletrolítico da dieta.

Fonte: Autor.
As rações experimentais (Tabela 1) foram formuladas para atender as recomendações nutricionais propostas por Rostagno et al. (2005), com exceção da proteína bruta (PB), que foi reduzida de acordo com os tratamentos $(20,5 ; 19,4 ; 18,3$ e $17,2 \%)$ e realizada a devida suplementação com aminoácidos sintéticos. Para tanto, foram realizadas as análises de $\mathrm{PB}$, do milho e farelo de soja, no Laboratório de Nutrição Animal da UNIOESTE.

O balanço eletrolítico das rações experimentais foi mantido através do uso de diferentes proporções de bicarbonato de sódio, sal comum e inerte. Os balanços eletrolíticos das rações experimentais foram calculados considerando o peso molecular de cada elemento químico, conforme apresentado por Patience (1990).

O período experimental foi de 12 dias, sendo os sete primeiros para adaptação às gaiolas e às rações experimentais e os cinco dias finais para coleta de fezes e urina. A quantidade de ração fornecida diariamente aos animais foi calculada com base no peso metabólico $\left(\mathrm{kg}^{0,75}\right)$. Para evitar perdas, e facilitar a ingestão, as rações foram umedecidas e fornecidas duas vezes ao dia (7h00min e 19h00min). A água foi fornecida à vontade após os animais terem consumido as rações experimentais.

A metodologia utilizada foi a de coleta total de fezes, mediante o uso do óxido de ferro como marcador fecal (2,0\% Fe2O3), a fim de determinar o início e o final do período de coleta. As quantidades coletadas foram pesadas diariamente, acondicionadas em sacos plásticos e armazenadas em freezer $\left(-18,0^{\circ} \mathrm{C}\right)$. Após o período de coleta as fezes foram descongeladas e homogeneizadas e, em seguida, as amostras foram secadas em estufa de ventilação forçada $\left(55,0^{\circ} \mathrm{C}\right)$, durante 72 horas.

A urina foi filtrada, medida e coletada diariamente (7h30min) em recipientes contendo 20mL de $\mathrm{HCl}$ 1:1 para evitar a proliferação bacteriana e possíveis perdas por volatilização. 
Após este procedimento, uma alíquota de 5,0\% do volume total foi acondicionada em recipiente de vidro e armazenada em refrigerador $\left(3,0^{\circ} \mathrm{C}\right)$ até a realização das análises laboratoriais.

Ao término da coleta de urina, destinadas às análises laboratoriais, foi realizada uma coleta de urina para determinação do $\mathrm{pH}$. Anteriormente foi realizada a limpeza das gaiolas de metabolismo, coletores de urina e recipientes de coleta, com o uso de água deionizada, e o ácido clorídrico não foi adicionado aos recipientes de coleta, com o intuito de não interferir no $\mathrm{pH}$ da urina (WOCHNER et al., 2012). A urina excretada foi imediatamente coletada e submetida à leitura do $\mathrm{pH}$.

Ao término do período experimental foram realizadas as coletas de sangue, após jejum alimentar de 12 horas, por meio de punção na veia jugular (OLIVEIRA et al., 2004), com auxílio de agulhas de $100 \mathrm{~mm}$ de comprimento. Foram colhidos aproximadamente $10 \mathrm{~mL}$ de sangue, que foram divididos em dois tubos do tipo Vacutainer, um contendo EDTA-K3 e outro contendo Fluoreto de sódio/oxalato. Os tubos foram centrifugados a $3000 \mathrm{rpm}$, por um período de 10 minutos, e posteriormente foi realizada a extração do plasma, com o auxílio de uma pipeta automática, que foi acondicionado em tubos do tipo eppendorf e armazenados sob refrigeração até a realização das análises bioquímicas.

As análises de glicose, colesterol, triglicerídeos, uréia e creatinina no plasma sanguíneo foram realizadas com o uso de kits bioquímicos específicos, seguindo os procedimentos recomendados pelo fabricante. As leituras das absorbâncias foram realizadas com o auxilio de um espectrofotômetro UV/Vis.

As análises de nitrogênio $(\mathrm{N})$ das fezes, urina e rações experimentais foram realizadas no Laboratório de Nutrição Animal da Universidade Estadual do Oeste do Paraná, de acordo com as técnicas descritas por Silva e Queiroz (2002).
Foram determinados o $\mathrm{N}$ ingerido, $\mathrm{N}$ excretado nas fezes e urina, $\mathrm{N}$ absorvido, $\mathrm{N}$ retido, $\mathrm{N}$ retido/ $\mathrm{N}$ absorvido e a excreção total de nitrogênio.

Os valores de proteína bruta consumida (PBC), excretada nas fezes (PBF) e na urina (PBU) foram obtidos por meio da multiplicação dos teores de proteína bruta pelas quantidades de ração consumida, de fezes e de urina excretadas, respectivamente. A partir desses valores determinou-se a proteína bruta retida $(\mathrm{PBR}=\mathrm{PBC}$ - PBF - PBU) e a utilização líquida de proteína $(\mathrm{ULP}=\mathrm{PBR} / \mathrm{PBC})$.

Os parâmetros avaliados foram submetidos às análises de variância e de regressão polinomial, em função dos níveis de proteína bruta das rações experimentais. As análises estatísticas foram realizadas com o auxílio do Sistema de Análises Estatísticas e Genéticas - SAEG, desenvolvido pela Universidade Federal de Viçosa (RIBEIRO JUNIOR, 2001).

\section{Resultados e Discussão}

Em condição de estresse térmico os valores médios de temperatura, umidade relativa do ar e índice de temperatura de globo e umidade (ITGU) foram de $28,77 \pm 1,66{ }^{\circ} \mathrm{C}, 77,95 \pm 5,51 \%$ e 78,44 $\pm 2,33$, respectivamente, sendo que a temperatura do ar foi superior à crítica máxima $\left(27^{\circ} \mathrm{C}\right)$ sugerida por Leal e Nããs (1992). O ITGU obtido aproximou-se de 81,2 obtido por Vaz et al. (2005), que consideraram como sendo uma situação de estresse por calor para suínos na mesma faixa de peso.

As condições de temperatura do ar registradas para a condição de conforto térmico encontramse na faixa considerada ideal para suínos, uma vez que os valores de temperatura, umidade relativa do ar e de ITGU foram de $18,13 \pm 3,96^{\circ} \mathrm{C}, 72,09$ $\pm 8,86 \%$ e $64,21 \pm 5,45$, respectivamente, pois Tolon et al. (2010) relataram que a temperatura 
do ar, considerada de conforto térmico, varia de 16 a $24{ }^{\circ} \mathrm{C}$. Da mesma forma, o ITGU está em conformidade com aquele de 70,4 obtido por Di Campos et al. (2008) para suínos mantidos em ambiente termoneutro.

Para a condição de estresse térmico, a redução dos níveis de proteína bruta na ração não influenciou $(\mathrm{P}>0,05)$ o $\mathrm{N}$ excretado nas fezes, $\mathrm{N}$ retido/ $\mathrm{N}$ absorvido e a utilização líquida de proteína (ULP) e em condição de conforto térmico não foram observadas diferenças $(\mathrm{P}>0,05)$ para todas as variáveis relacionadas ao balanço de nitrogênio (Tabela 2).

$\mathrm{O} \mathrm{N}$ ingerido, em condições de conforto térmico, não variou em função dos níveis de proteína bruta da dieta. Shriver et al. (2003), trabalhando com suínos na fase de crescimento, também observaram que a redução dos níveis de PB na ração, de 18 para 14\%, não influenciou as quantidades de $\mathrm{N}$ ingerido.

No entanto, em condições de estresse térmico observou-se uma redução linear ( $\mathrm{Y}=-0,00706+$ 1,3954X; $\mathrm{R}^{2}=0,98$ ) do $\mathrm{N}$ ingerido (Tabela 2), o que está de acordo com os resultados encontrados por Orlando et al. (2007). De acordo com Lazzeri et al. (2011) a redução na ingestão de nitrogênio, neste caso, seria esperada, uma vez que o consumo diário de ração dos animais foi estabelecido com base no peso metabólico, associado à diferença do nível de proteína bruta dos tratamentos.

$\mathrm{O} \mathrm{N}$ excretado nas fezes não foi influenciado $(\mathrm{P}>0,05)$ pelos níveis de proteína bruta da dieta, tanto em condição de conforto quanto de estresse térmico, mesmo havendo redução do $\mathrm{N}$ ingerido em condição de estresse térmico. Zangeronimo et al. (2007a), avaliando diferentes níveis de lisina digestível e PB na ração, também não encontraram diferenças $(\mathrm{P}>0,05)$ para o $\mathrm{N}$ excretado nas fezes.

$\mathrm{O} \mathrm{N}$ excretado na urina, em condição de estresse térmico, reduziu linearmente ( $\mathrm{Y}=$ $\left.-2,9229+0,5369 \mathrm{X} ; \mathrm{R}^{2}=0,80\right)$, mostrando uma resposta diretamente proporcional aos níveis de proteína bruta da dieta, que pode ser devido aos excessos e/ou imbalanços de aminoácidos na ração aumentarem a excreção de nitrogênio na urina, o que pode ser verificado em rações com níveis mais elevados de proteína bruta. Além disso, a redução do $\mathrm{N}$ excretado na urina também pode estar relacionado à respectiva redução no $\mathrm{N}$ ingerido, uma vez que esta variável também apresentou uma resposta semelhante, associado ao fato do $\mathrm{N}$ excretado nas fezes não ter sido influenciado pela redução da proteína bruta da dieta com a respectiva suplementação de aminoácidos sintéticos.

Os resultados observados para $\mathrm{N}$ excretado na urina confirmam que o fornecimento de rações com menor teor de proteína reduz a quantidade de nitrogênio que é eliminado pelos suínos e confirma a hipótese de que esta estratégia nutricional é uma ferramenta de grande utilidade para evitar o excesso de nitrogênio nos dejetos líquidos (KERR et al., 2003). Por outro lado, em condição de conforto térmico, não foram observadas diferenças $(\mathrm{P}>0,05)$ para o $\mathrm{N}$ excretado na urina, seguindo as respostas obtidas para o $\mathrm{N}$ ingerido e $\mathrm{N}$ excretado nas fezes, que influenciaram diretamente na excreção total de $\mathrm{N}$, uma vez que esta é dependente do da excreção de $\mathrm{N}$ nas fezes e urina. Os coeficientes de variação observados para estas variáveis também podem ter colaborado para a obtenção destes resultados.

A excreção total de $\mathrm{N}$, em condição de estresse térmico, também reduziu linearmente ( $\mathrm{Y}$ $\left.=-0,4191+0,8454 \mathrm{X} ; \mathrm{R}^{2}=0,99\right)$ à medida que a proteína bruta da dieta foi reduzida, com a devida suplementação de aminoácidos sintéticos. Esta resposta está relacionada à redução do $\mathrm{N}$ excretado na urina, uma vez que o $\mathrm{N}$ excretado nas fezes foi semelhante entre os tratamentos avaliados, pois, de acordo com McLeod (1997) os aminoácidos absorvidos, e que estão em excesso em relação ao primeiro limitante, são oxidados e excretados como compostos nitrogenados. Entretanto, a degradação do excesso de aminoácidos tem alto 
et al. (2008), o N na uréia plasmática é um eficiente parâmetro para indicar a utilização dos aminoácidos dietéticos pelo suíno.

Tabela 3 - Parâmetros sanguíneos e pH urinário de suínos machos castrados, na fase inicial, submetidos a dietas com redução de proteína bruta, e suplementação com aminoácidos sintéticos, mantidos em condição de estresse e conforto térmico.

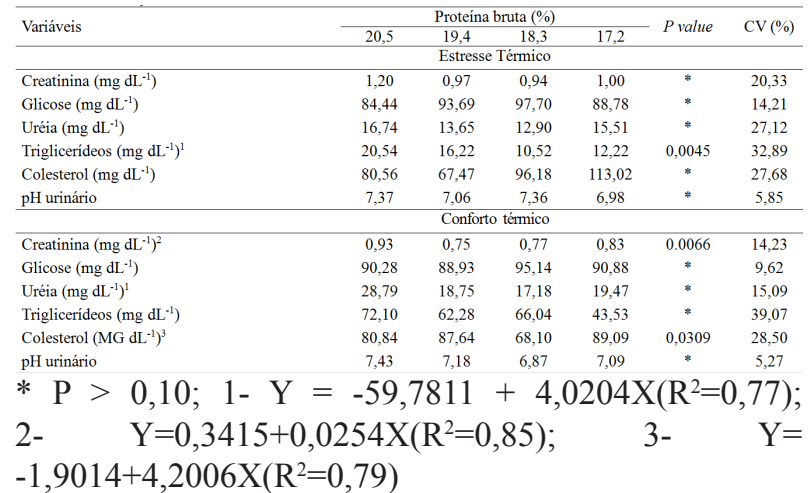

\section{Fonte: Autor.}

Em trabalho realizado por Lohmann et al. (2012), a creatinina aumentou $(\mathrm{P}=0,067)$ à medida que os níveis de valina digestível aumentaram. O teor de creatinina pode ser usado como indicador da qualidade da proteína dietética, pois o aumento do catabolismo muscular eleva as concentrações de creatinina sanguínea (VAZ et al., 2005). Os resultados do presente trabalho permitem supor que a diferença de absorção entre aminoácidos de origem cristalina e provenientes dos alimentos não altera a passagem destes nutrientes no trato gastrointestinal para o sangue (ZANGERONIMO, 2007b).

Em condição de estresse e conforto térmico os níveis de proteína bruta da ração não influenciaram as concentrações de glicose. Gómez et al. (2002) também não encontraram diferenças significativas para esta variável em trabalho com redução da proteína bruta.

O colesterol pode ser controlado pelo estado nutricional, pelos teores dietéticos de gordura e fatores hormonais (MENDONÇAJUNIOR, 1996), assim, um organismo possuidor de controle enzimático normal, mediante altas ingestões de colesterol, promove a redução de sua síntese orgânica, mantendo os níveis de colesterol estáveis (NABER, 1990). Portanto, o aumento do colesterol no plasma está mais relacionado com as quantidades de energia e gordura saturada ingeridas do que da própria ingestão do colesterol em si (MENDONÇA JUNIOR, 1996). Desta forma, os níveis de proteína bruta não influenciaram os níveis plasmáticos de colesterol e triglicerídeos, em condição de estresse e conforto térmico, respectivamente.

\section{Conclusão}

A redução da proteína bruta da dieta de 20,5 a 17,2\% é uma alternativa eficiente para diminuir a quantidade de nitrogênio excretado pelos suínos. Contudo, as rações com baixos teores de proteína propiciaram menor retenção de nitrogênio, mesmo suplementadas com aminoácidos sintéticos em condição de estresse térmico. Para condição de conforto térmico ocorreu redução na quantidade de creatinina e colesterol plasmático de suínos na fase inicial.

\section{Referências}

COMA, J.; ZIMMERMAN, D. R.; CARRION, D. Relationship of rate lean tissue growth and other factors to concentration of urea in plasma of pigs. Journal of Animal Science, Champaign, v. 73, n. 12, p. 3649-3656, 1995.

DI CAMPOS, M. S.; SODRÉ, L. R. Q. A.; MACHADO, A. A.; SAVASTANO JÚNIOR, H. Efeito da redução da proteína bruta da ração para suínos mantidos em termoneutralidade. Ciência e Tecnologia de Alimentos, Campinas, v. 28, n. 1, p. 7-11, 2008.

FRAGA, A. L.; MOREIRA, I.; FURLAN, A. C.; BASTOS, A. O.; OLIVEIRA, R. P.; MURAKAMI, A. E. Lysine requirement of starting barrows from two genetic groups, fed on low crude protein diets. Brazilian Archives of Biology and Technology, Curitiba, v. 51, n. 1, p. 49-56, 2008. 
GÓMEZ, R. S.; LEWIS, A. J.; MILLER, P. S.; CHEN, H. Y. Growth performance, diet apparent digestibility, and plasma metabolite concentrations of barrows fed corn soybean meal diets or low-protein, amino acid-supplemented diets at different feeding levels. Journal of Animal Science, Champaign, v. 80, n. 3, p. 644-653, 2002.

KERR, B. J.; SOUTHERN, L. L.; BIDNER, T. D.; FRIESEN, K. G.; EASTER, R. A. Influence of dietary protein level, amino acid supplementation, and dietary energy levels on growing-finishing pig performance and carcass composition. Journal of Animal Science, Champaign, v. 81, v. 12, p. $3075-$ 3087, 2003.

LAZZERI, D. B.; POZZA, P. C.; POZZA, M. S. S.; BRUNO, L. D. G.; PASQUETTI, T. J.; CASTILHA, L. D. Balanços metabólicos de suínos alimentados com rações referências e inclusões de farelo de soja. Revista Brasileira de Saúde e Produção Animal, Salvador, v. 12, n. 4, p. 984-995, 2011.

LEAL, P. M.; NÃÃS, I. A. Ambiência animal. In: CORTEZ, L. A. B.; MAGALHÃES, P. S. G. (Org.). Introdução à engenharia agrícola. Campinas: Unicamp. 1992. p. 121-135.

LOHMANN, A. C.; POZZA, P. C.; POZZA, M. S. S.; NUNES, R. V.; CASTILHA, L. D.; POSSAMAI, M.; BRUNO, L. D. G.; LAZZERI, D. B. Níveis de valina digestível para suínos machos castrados dos 15 aos 30 kg. Archivos de Zootecnia, Córdoba, v. 61, n. 234, p. 268, 2012.

LORDELO, M. M.; GASPAR, A. M.; LE BELLEGO, L.; FREIRE, J. P. Isoleucine and valine supplementation of low-protein corn-wheat-soybean meal based diet for piglets: growth performance and nitrogen balance. Journal of Animal Science, Champaign, v. 86, n. 11, p. 2936-2941, 2008.

MCLEOD, M. G. Effects of amino acid balance and energy: protein ratio on energy and nitrogen metabolism in male broiler chickens. British Poultry Science, Edinburgh, v. 38, n. 4, p. 405-411, 1997.

MENDONÇA JUNIOR, C. X. Colesterol no ovo: possibilidades de sua redução. In: SIMPÓSIO LATINO AMERICANO DE NUTRIÇÃO DE SUÍNOS E AVES, Campinas. Anais... Campinas: Colégio Brasileiro de Nutrição Animal, 1996. p. 87117.
NABER, E. C. Cholesterol content of eggs: can and should the industry try to change it? Feedstuffs, Bloomington, v. 62, n. 5, p. 46-52, 1990.

OLIVEIRA, G. C.; MOREIRA, I.; FURLAN, A.C.; BASTOS, A. O.; FRAGA, A. L. Efeito das dietas de baixo teor de proteína bruta, suplementadas com aminoácidos, para leitões machos castrados (15 a 30 kg). Revista Brasileira de Zootecnia, Viçosa, v.33, n.6, p.1747-1757, 2004.

OLIVEIRA, V.; FIALHO, E. T.; LIMA, J. A. F.; ARAÚJO, J. S. Metabolismo do nitrogênio em suínos alimentados com dietas contendo baixos teores de proteína bruta. Revista Brasileira de Agrociência, Pelotas, v. 13, n. 2, p. 257-260, 2007.

OLIVEIRA, V.; FIALHO, E. T.; LIMA, J. A. F.; BERTECHINI, A. G.; FREITAS, R. T. F. Teor de proteína no metabolismo do nitrogênio e da energia em suínos durante o crescimento. Ciência e Agrotecnologia, Lavras, v. 29, n. 4, p. 866-874, 2005.

ORLANDO, U. A. D.; OLIVEIRA, R. F. M.; DONZELE, J. L.; SILVA, F. C. O.; GENEROSO, R. A. R.; SIQUEIRA, J. C. Níveis de proteína bruta e suplementação de aminoácidos em rações para leitoas dos 30 aos $60 \mathrm{~kg}$ mantidas em ambiente de alta temperatura. Revista Brasileira de Zootecnia, Viçosa, v. 36, n. 5, p. 1573-1578, 2007.

PAIANO, D.; MOREIRA, I.; SILVESTRIN, N.; CARVALHO, P. L. O.; SILVA, M.A.A.; PERDIGÃO, L. S. Relações treonina:lisina digestíveis para suínos na fase inicial, alimentados com rações de baixa proteína, calculadas de acordo com o conceito de energia líquida. Arquivo Brasileiro de Medicina Veterinária e Zootecnia, Belo Horizonte, v. 61, n. 1, p. 211-218, 2009.

PATIENCE, J. F. A review of the role acid-base balance in amino acid nutrition. Journal of Animal Science, Savoy, v. 68, n. 2, p. 398-408, 1990.

PEKAS, J. C. Versatible swine labotarory apparatus for physiologic and metabolic studies. Journal of Animal Science, Champaign, v. 27, n. 5, p. 13031306, 1968.

RIBEIRO JUNIOR, J. I. Análise estatística no SAEG. Viçosa: UFV, 2001. 
RODRIGUES, N. E. B.; FIALHO, E. T.; ZANGERONIMO, M. G.; CANTARELLI, V. S.; RODRIGUES, P. B.; FILHO, M. R.; FILHO, M. R.; GOMIDES, E. M.; BETARELLI, R. P. Reduction in the protein level and addition of oil in diets for finishing pugs under different temperatures. Revista Brasileira de Zootecnia, Viçosa, v. 41, n. 8, p. 1878-1883, 2012.

ROSTAGNO, H. S.; ALBINO, L. F. T.; DONZELE, J. L.; GOMES, P. C.; FERREIRA, A. S.; OLIVEIRA, R. F. M.; LOPES, D. C. Tabelas brasileiras para suínos e aves: composição de alimentos e exigências nutricionais. 2. ed. Viçosa: UFV, 2005.

SHRIVER, J. A.; CARTER, S. D.; SUTTON, A. L.; RICHERT, B. T.; SENNE, B. W.; PETTEY, L. A. Effects of adding fiber sources to reduced-crude protein, amino acid-supplemented diets on nitrogen excretion, growth performance, and carcass traits of finishing pigs. Journal Animal Science, Champaign, v. 81, n. 2, p. 492502, 2003.

SILVA, D. J.; QUEIROZ, A. C. Análise de alimentos: métodos químicos e biológicos. 3. ed. Viçosa: Ed. UFV, p. 235, 2002.

TOLEDO, J. B.; FURLAN, A. C.; POZZA, P. C.; CARRARO, J.; MORESCO, G.; FERREIRA, S. L.; GALLEGO, A. G. Reduction of the crude protein content of diets supplemented with essential amino acids for piglets weighing 15 to 30 kilograms. Revista Brasileira de Zootecnia, Viçosa, v. 43, n. 6, p. 301-309, 2014.

TOLON, Y. B.; BARACHO, M. S.; NÄÄS, I. A.; ROJAS, M.; MOURA, D. J. Ambiência térmica, aérea e acústica para reprodutores suínos. Engenharia Agrícola, Jaboticabal, v. 30, n. 1, p. 1-13, 2010.

VAZ, R. G. M. V.; OLIVEIRA, R. F. M.; DONZELE, J. L.; FERREIRA, A. S.; BRUSTOLINI, P. C.; KIEFER, C.; ORLANDO, U. A. D. Exigência de aminoácidos sulfurados digestíveis para suínos machos castrados mantidos em ambiente termoneutro dos 15 aos $30 \mathrm{~kg}$. Arquivo Brasileiro de Medicina Veterinária e Zootecnia, Belo Horizonte, v. 57, n. 3, p. 345-352, 2005.

ZANGERONIMO, M. G.; FIALHO, E. T.; MURGAS, L. D. S.; FREITAS, R. T. F.; RODRIGUES, P. B. Desempenho e excreção de nitrogênio de leitões dos 9 aos $25 \mathrm{~kg}$ alimentados com dietas com diferentes níveis de lisina digestível e proteína bruta. Revista Brasileira de Zootecnia, Viçosa, v. 36, n. 5, p. 1382-1387, 2007a.
ZANGERONIMO, M. G.; FIALHO, E. T.; MURGAS, L. D. S.; LIMA, J. A. F.; ROCHA, E. V. H.; ALVARENGA, R. R. Efeito de níveis de lisina digestível verdadeira e proteína bruta na dieta sobre parâmetros morfo-fisiológicos e utilização do nitrogênio em suínos na fase inicial. Ciência e Agrotecnologia, Lavras, v. 31, n. 2, p. 506-513, 2007 b.

WOCHNER, M. O.; POZZA, P. C.; NUNES, R. V.; POZZA, M. S. S.; LOHMAN, A. C.; BRUNO, L. D. G.; RODRIGUES, M.; PASQUETTI, T. J. Parâmetros bioquímicos sanguíneos, balanço de nitrogênio e metabolizabilidade da energia bruta em suínos alimentados com dietas contendo diferentes balanços eletrolíticos. Semina Ciências Agrárias, Londrina, v. 33, n. 4, p. 1599-1608, 2012.

WOLP, R. C.; RODRIGUES, N. E .B.; ZANGERONIMO, M. G.; CANTARELLI, V. S.; FIALHO, E. T.; PHILOMENO, R.; ALVARENGA, R. R.; ROCHA, L. F. Soybean oil and crude protein levels for growing pigs kept under heat stress conditions. Livestock Science, Kidlington, v. 147, p. 148-153, 2012.
Recebido em: 31 mar. 2014 Aceito em: $30 \mathrm{dez} .2014$. 
